Article

\title{
Stages in the Dynamics of Hydrate Formation and Consequences for Design of Experiments for Hydrate Formation in Sediments
}

\author{
Bjørn Kvamme ${ }^{1, *}$, Richard B. Coffin ${ }^{1}$, Jinzhou Zhao ${ }^{1}$, Na Wei ${ }^{1}$, Shouwei Zhou ${ }^{1}$, Qingping Li ${ }^{2}$, \\ Navid Saeidi ${ }^{3}$, Yu-Chien Chien ${ }^{4} \mathbb{D}^{\circ}$, Derek Dunn-Rankin $\left.{ }^{3,4}{ }^{(}\right)$, Wantong Sun ${ }^{1}$ \\ and Mojdeh Zarifi ${ }^{5}$ \\ 1 State Key Laboratory of Oil and Gas Reservoir Geology and Exploitation, Southwest Petroleum University, \\ Xindu Road No.8, Chengdu 610500, China \\ 2 CNOOC Research Institutes Limited Liability Company, Taiyanggong South Road No.6, Beijing 10027, China \\ 3 Environmental Engineering Department, University of California, Irvine, CA 92697-3975, USA \\ 4 Mechanical and Aerospace Engineering Department, University of California, Irvine, CA 92697-3975, USA \\ 5 Department of Physics and Technology, University of Bergen, Bergen 5007, Norway \\ * Correspondence: bkvamme@strategic-carbonllc.com; Tel.: +86-47-93451956
}

Received: 8 July 2019; Accepted: 23 August 2019; Published: 3 September 2019

\begin{abstract}
Natural gas hydrates in sediments can never reach thermodynamic equilibrium. Every section of any hydrate-filled reservoir is unique and resides in a stationary balance that depends on many factors. Fluxes of hydrocarbons from below support formation of new hydrate, and inflow of water through fracture systems leads to hydrate dissociation. Mineral/fluid/hydrate interaction and geochemistry are some of the many other factors that determine local hydrate saturation in the pores. Even when using real sediments from coring it is impossible to reproduce in the laboratory a natural gas hydrate reservoir which has developed over geological time-scales. In this work we discuss the various stages of hydrate formation, with a focus on dynamic rate limiting processes which can lead to trapped pockets of gas and trapped liquid water inside hydrate. Heterogeneous hydrate nucleation on the interface between liquid water and the phase containing the hydrate former rapidly leads to mass transport limiting films of hydrate. These hydrate films can delay the onset of massive, and visible, hydrate growth by several hours. Heat transport in systems of liquid water and hydrate is orders of magnitude faster than mass transport. We demonstrate that a simple mass transport model is able to predict induction times for selective available experimental data for $\mathrm{CO}_{2}$ hydrate formation and $\mathrm{CH}_{4}$ hydrate formation. Another route to hydrate nucleation is towards mineral surfaces. $\mathrm{CH}_{4}$ cannot adsorb directly but can get trapped in water structures as a secondary adsorption. $\mathrm{H}_{2} \mathrm{~S}$ has a significant dipole moment and can adsorb directly on mineral surfaces. The quadropole-moment in $\mathrm{CO}_{2}$ also plays a significant role in adsorption on minerals. Hydrate that nucleates toward minerals cannot stick to the mineral surfaces so the role of these nucleation sites is to produce hydrate cores for further growth elsewhere in the system. Various ways to overcome these obstacles and create realistic hydrate saturation in laboratory sediment are also discussed.
\end{abstract}

Keywords: hydrate; phase transitions; nucleation; hydrate films

\section{Introduction}

Natural gas hydrates are crystalline compounds which are mainly stabilized by hydrogen bonds that forms cavities which enclathrate small hydrocarbons. Inorganic gases, like for instance $\mathrm{CO}_{2}$ and $\mathrm{H}_{2} \mathrm{~S}$, also form hydrates. The extra stabilization of the water structure by the inclusion of these "guest" molecules makes hydrates stable also for temperatures above zero Celsius if the pressure 
is high enough. The formation of these ice-like compounds during processing and transport of hydrocarbons has motivated substantial amounts of hydrate research in the past. The enormous quantity of natural gas hydrates spread around the world stimulates creativity in development of new methods for commercial dissociation and use of these energy sources. Adding steam or hot water for thermal dissociation of the hydrate is very expensive. Substantial portions of the added heat are lost to minerals. Adding chemicals is also very expensive. The pressure reduction method is the approach that has drawn the most attention in the past. In this method the local pressure is reduced to below the stability limit pressure of the hydrate. One drawback of the pressure reduction method is that the heat necessary for dissociation of the hydrate still needs to be supplied. Studies conducted on pilot plant scale [1-4] have so far not been successful, and freezing down (from the heat drawn away by dissociation demand) has been only one of several problems. Production of sand and water are other drawbacks. In addition to the stability limit considerations, hydrate dissociation in sediment is limited by the transport processes across a thin interface $(1.2 \mathrm{~nm})$ between the hydrate and surrounding phases. These phase transition dynamics are implicitly coupled to the dynamics of the flow and all phase transitions in every pore. Finally, the coupled dynamics of all pores are connected to the reservoir flow. Pressure reduction attacks the top level of dynamics. The transfer of the impact all the way down to the phase transition dynamics will impose significant delays. Hence, pressure reduction is a slow method from a theoretical point of view. An experimental challenge for pressure reduction is to establish realistic boundary conditions that can supply heat from surrounding sediments. Many published experiments even report pressure reduction experiments at constant temperature as controlled by surrounding heat baths. Temperature changes, on the other hand, distribute very rapidly through liquid water and hydrate, making thermal approaches dynamically efficient.

The strong focus on reduction of $\mathrm{CO}_{2}$ emissions during the latest two decades has also triggered rapid development of various ways to utilize $\mathrm{CO}_{2}$, like for instance the use of $\mathrm{CO}_{2}$ for enhanced oil recovery. The use of $\mathrm{CO}_{2}$ for production of natural gas hydrate is another option. The exchange between $\mathrm{CH}_{4}$ hydrate and $\mathrm{CO}_{2}$ hydrate is possible through two primary mechanisms. The first mechanism is a solid-state exchange which has been verified experimentally for temperatures substantially inside the ice region for water [5,6] and also theoretically through molecular dynamics (MD) simulations [7]. For temperatures above freezing the water surrounding the hydrate in the pores is a combination of liquid water and pore bounded water. A typical hydrate saturation for Alaska is $75 \%$ or lower, like in the area used for the Ignik Sikimu pilot test [8,9]. Hydrate saturation is the percentage of available pore volume that is filled with hydrate. For temperatures in the liquid water region another mechanism $[10,11]$ than solid state conversion is possible. Injected $\mathrm{CO}_{2}$ will form new hydrate with free pore water. Released heat from this hydrate formation, and other factors, will dissociate the in situ hydrate. Similar to the formation of $\mathrm{CH}_{4}$ hydrate the formation of a new $\mathrm{CO}_{2}$ hydrate will also go through the various stages of the hydrate formation process. From a physical point of view any fluid/solid phase transition in the classical regime consists of two stages. The nucleation of hydrate requires that the free energy change of the formation be negative and the free energy difference has to be large enough to supply the work needed to push away the molecules in the original phases. The necessary hydrate particle volume needed to win the competition between benefits of the phase transition, and the penalty of the push work, is the critical size hydrate core. After this first nucleation stage the hydrate will grow steadily. but will compete with other hydrate cores for mass, and may diminish in competition with more stable cores. And also in the steady growth stage the heat released from the growth of neighboring hydrate cores can lead to dissociation. Also, as discussed further later, dilution of fluid phases will lead to dissociation. Even the two physically well-defined stages of hydrate growth are fairly complex in non-equilibrium systems. Rapid formation of hydrate films on the interface between hydrate former phase and water leads to a dramatic slow-down in supply of hydrate formers from typical liquid phase diffusivity (coefficients in the order of $10^{-7} \mathrm{~m}^{2} / \mathrm{s}$ to $10^{-8}$ $\mathrm{m}^{2} / \mathrm{s}$ ) down to diffusivity for transport through hydrate (coefficient from $10^{-15} \mathrm{~m}^{2} / \mathrm{s}$ to $10^{-17} \mathrm{~m}^{2} / \mathrm{s}$ ). Dramatic reduction in mass transport rates and limited shear forces (limited or no flow) lead to very 
long times, relative to the typical nanoseconds time scale for nucleation, before visible hydrate can be observed at millimeter scales. In addition to the nucleation stage and the growth stage the term induction frequently occurs in the open literature. This time can be defined as the time to reach visible hydrate or to reach the onset of massive hydrate growth rate (depends on monitoring method resolution).

We utilize classical nucleation theory (CNT) and residual thermodynamics to examine the dynamics of hydrate formation. This is used as the basis for considering various ways to break hydrate films and increase formation rate. The primary goal is to shed light on how to design laboratory experiments for hydrate formation between water and $\mathrm{CH}_{4}$ or $\mathrm{CO}_{2}$ in sediments. Reducing trapped gas pockets and trapped liquid water to a minimum will be an important step towards creating hydrates in sediments that in important ways can be compared to natural gas hydrates in nature.

\section{Methodologies}

Kvamme and Tanaka [12] used MD simulations to calculate the chemical potentials of water in ice and empty clathrates of structures I and II hydrate. They then used experimental data for heat of freezing at zero Celsius and experimental data for specific heat capacity of liquid water in order to get a continuous description of water chemical potential. Ideal gas chemical potential for the three phases (ice, empty clathrate of structure I and empty clathrate of structure II) were trivially sampled from momentum space during the MD simulations. The values calculated by Kvamme and Tanaka [12] are plotted in Figure 1 along with parameters listed in Table 1. Gas (or fluid phases) of $\mathrm{CH}_{4}$ and $\mathrm{CO}_{2}$ are modelled using residual thermodynamics in the manner that is similar for gas/liquid equilibrium in hydrocarbon systems. For this purpose we utilize the Soave-Redlich-Kwong (SRK) equation of state [13]. The only difference is that we use chemical potential rather than fugacity. For that reason, the gas phase needs model molecules for the ideal gas term for $\mathrm{CH}_{4}$ and $\mathrm{CO}_{2} \cdot \mathrm{CH}_{4}$ is modelled as a spherical molecule and the ideal gas chemical potential is an analytical integral over the Boltzmann factors of translational momentums in the $\mathrm{x}, \mathrm{y}$ and $\mathrm{z}$ directions. The equations for this can be found in any textbook on physical chemistry or statistical mechanics and are not repeated here. The model we use for $\mathrm{CO}_{2}$ is a linear molecule with only two independent rotational degrees of freedom with equal moments of inertia due to the symmetry. The translational part is given by the molecular weight and the center of mass. For completeness we also give the three rotational momentums for the water model utilized in our earlier study so that it will be possible to reproduce the results presented in this work in Table 2 below.

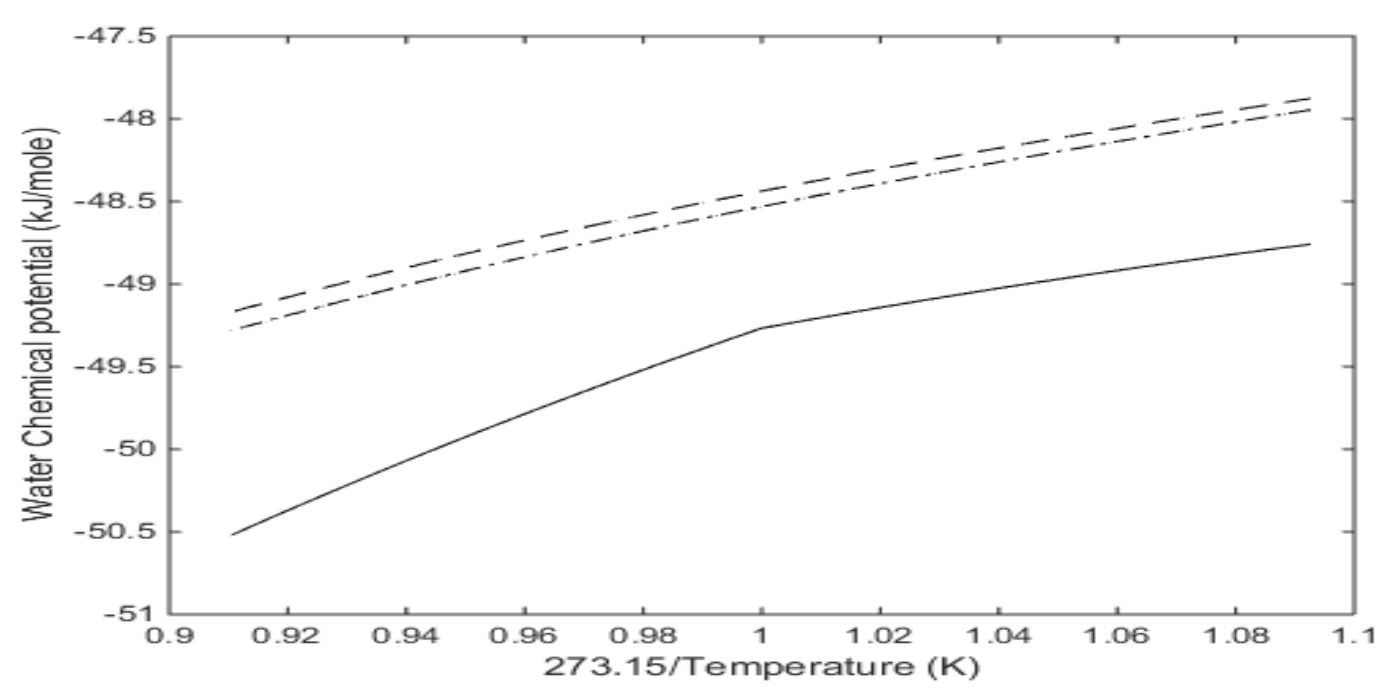

Figure 1. Water chemical potential in empty hydrate of structure I (dash), and in empty hydrate of structure II (dash-dot). Water chemical potential in the ice region $(273.15 / \mathrm{T} \geq 1.0)$ and liquid region $(273.15 / \mathrm{T}<1.0)$ is represented by a solid curve. 
Table 1. Coefficients $a_{i}$ for chemical potential of water in various phases; $\mu_{\mathrm{H}_{2} \mathrm{O}}=\sum_{i=1}^{i=6} a_{i}\left(\frac{T_{\mathrm{C}_{\mathrm{H}_{2} \mathrm{O}}}}{T}\right)^{(i-1)}$ with $T_{C_{\mathrm{H}_{2} \mathrm{O}}}=647.096 \mathrm{~K}$.

\begin{tabular}{ccccc}
\hline $\boldsymbol{i}$ & $\begin{array}{c}\text { Str. I } \\
\boldsymbol{a}_{\boldsymbol{i}}(\boldsymbol{k J} / \text { mole })\end{array}$ & $\begin{array}{c}\text { Str. II } \\
\boldsymbol{a}_{\boldsymbol{i}}(\boldsymbol{k J} / \text { mole })\end{array}$ & $\begin{array}{c}\text { Liquid } \\
\boldsymbol{a}_{\boldsymbol{i}}(\boldsymbol{k J} / \text { mole })\end{array}$ & $\begin{array}{c}\text { Ice } \\
\boldsymbol{a}_{\boldsymbol{i}}(\boldsymbol{k J} / \text { mole })\end{array}$ \\
\hline 1 & -90.48377 & -92.72076 & -109.03432 & -87.13485 \\
2 & 42.46997 & 45.09842 & 58.33379 & 41.31529 \\
3 & -14.61482 & -15.72658 & -19.48522 & -17.71143 \\
4 & 1.76419 & 1.92639 & 2.32631 & 3.88149 \\
5 & 0 & 0 & 0 & -0.43451 \\
6 & 0 & 0 & 0 & 0.01971 \\
\hline
\end{tabular}

Table 2. Moments of inertia for $\mathrm{H}_{2} \mathrm{O}$ and $\mathrm{CO}_{2}$ models utilized.

\begin{tabular}{ccc}
\hline Axis & $\mathbf{H}_{\mathbf{2}} \mathbf{O}$ Moment of Inertia $\left.\mathbf{( k g} \cdot \mathbf{m}^{\mathbf{2}}\right)$ & $\mathbf{C O}_{\mathbf{2}}$ Moment of Inertia $\left.\mathbf{( k g} \cdot \mathbf{m}^{\mathbf{2}}\right)$ \\
\hline $\mathrm{x}$ & $2.938 \cdot 10^{-47}$ & $0.7173 \cdot 10^{-45}$ \\
$\mathrm{y}$ & $1.020 \cdot 10^{-47}$ & $0.7173 \cdot 10^{-45}$ \\
$\mathrm{z}$ & $1.918 \cdot 10^{-47}$ & 0 \\
\hline
\end{tabular}

More advanced theories, like for instance phase field theories [14-18], may be more rigorous in the implicit couplings between the various contributions to the phase transition dynamics but are also more complex in terms of distinguishing between the various stages of hydrate growth. Classical nucleation theory (CNT) is still rigorous enough to illustrate nucleation times. In principle CNT can be used to determine two parameters related to volume and shape of a hydrate core [19] in transition to growth. For the main goal of this work, however, we stick to a spherical model. A critical size hydrate core is defined as the size when the hydrate core enters the stable growth period.

We also limit ourselves to some of the important hydrate phase transitions involved in hydrate formation in porous media. Formation of hydrate on the interface between a separate phase containing hydrate formers, and hydrate formation towards mineral surfaces, are the two fastest routes. When these two routes have created a hydrate film there will also be some hydrate formation from dissolved hydrate former in water. For methane this is limited by fairly low solubility, while the higher solubility of $\mathrm{CO}_{2}$ in water makes this route far more significant.

In order for a hydrate particle to reach critical size, the hydrate former molecules must be transported from an outer boundary on the liquid water side and through an interface layer of gradually increased water structure. The more structured the water, the slower the transport. The necessary time for enough hydrate former molecules to reach surface of the hydrate core at critical size is the nucleation time. Further growth through the hydrate film is very slow as indicated above. Since heat transport is very fast, and maybe two to three orders of magnitude faster than mass transport in liquid water, it will be several orders of magnitude faster than mass transport through hydrate. Assuming a constant mass transport rate through the hydrate film in order to supply the hydrate film with hydrate formers we are then able to estimate hydrate film thickness as a function of time. This will provide a basis for evaluating the necessary dynamics needed to break hydrate films, and correspondingly ensure that measures can be taken to prevent blocking hydrate films.

\subsection{Hydrate Formation from Water and a Separate Phase Containing Hydrate Formers}

Hydrate phase transition along the equilibrium curve is reversible. At equilibrium the free energy changes of the hydrate formation from liquid water (or ice) and hydrate formers coming from 
gas, liquid or fluid state is zero. Outside of equilibrium the molar free energy change, as given by Equation (1) below, has to be negative.

$$
\begin{aligned}
& \Delta G^{\left(H_{1}\right)}=x_{H_{2} \mathrm{O}}^{H_{1}}\left(\mu_{H_{2} O}^{H_{1}}\left(T, P, \vec{x}^{H_{1}}\right)-\mu_{H_{2} O}^{\text {water }}(T, P, \vec{x})\right) \\
& +\sum_{i} x_{i}^{H_{1}}\left(\mu_{i}^{H_{1}}\left(T, P, \vec{x}^{H_{1}}\right)-\mu_{i}^{\text {gas }}\left(T, P, \vec{y}^{\text {gas }}\right)\right)
\end{aligned}
$$

The superscript $H_{1}$ denotes this specific heterogeneous phase transition. $\mathrm{T}$ is temperature, $\mathrm{P}$ is pressure. $x$ is mole-fraction in either liquid or hydrate (denoted with a superscript $H$ ). $y$ is mole-fraction in gas (or liquid, or fluid) hydrate former phase; $i$ is an index for hydrate formers. Superscript water denotes a water phase. Generally this is ice, liquid or adsorbed water on mineral surfaces. In this work we only consider liquid water; $\mu$ is chemical potential. $x$ is mole-fraction in liquid water or hydrate (as given by superscripts). Vector sign denote mole-fractions of all components in the actual phase.

Symmetric excess formulation for liquid water chemical potential is given by:

$$
\mu_{\mathrm{H}_{2} \mathrm{O}}^{\text {water }}(T, P, \vec{x})=\mu_{\mathrm{H}_{2} \mathrm{O}}^{\text {pure } \mathrm{H}_{2} \mathrm{O}}(T, P)+R T \ln \left[x_{\mathrm{H}_{2} \mathrm{O}} \gamma_{\mathrm{H}_{2} \mathrm{O}}(T, P, \vec{x})\right] \approx \mu_{\mathrm{H}_{2} \mathrm{O}}^{\text {pure, } \mathrm{H}_{2} \mathrm{O}}(T, P)+R T \ln \left[x_{\mathrm{H}_{2} \mathrm{O}}\right]
$$

$\lim \left(\gamma_{\mathrm{H}_{2} \mathrm{O}}\right)=1.0$ when $x_{\mathrm{H}_{2} \mathrm{O}}$ approaches unity.

Water as superscript on the left-hand side distinguishes liquid water phase from water in the hydrate phase. A right-hand side approximation of Equation (2) is not necessary but good enough for the purpose of this work. The alternative would be to use a model for the activity coefficient or utilization of the Gibbs-Duhem relation. In our phase field theory (PFT) modelling of $\mathrm{CO}_{2}$ hydrate phase transition dynamics studies [14,15] we used the latter approach. Our PFT models are fairly complex and a simpler kinetic model might be more useful in order to visualize the various stages of the hydrate formation.

Water chemical potential in the hydrate structure is given by [16]:

$$
\mu_{\mathrm{H}_{2} \mathrm{O}}^{\mathrm{H}}=\mu_{\mathrm{H}_{2} \mathrm{O}}^{\mathrm{O} H}-\sum_{k=1,2} R T v_{k} \ln \left(1+\sum_{i} h_{i j}\right)
$$

$H$ denotes hydrate and superscript $O$ on first term on right hand side denotes empty clathrate. Calculated values for water chemical potentials in empty hydrates of structure I and II are readily available from model water (TIP4P) simulations [12] as discussed above. Cavities per water in structure I hydrate, $v_{k}$ is $1 / 23$ for small cavities and $3 / 23$ for large cavities. $h_{k i}$ is the canonical partitition function for s guest of type $i$ in cavity type $k$. For a rigid water lattice the result is a Boltzmann integral over all possible water-guest and guest-guest interactions and a function of the free energy of the huest molecule [12]. This is the most common way to calculate $h_{k i}$ in various available codes for hydrate equilibrium. A different formulation of $h_{k i}$ utilize a perturbation approach in which the movements of the guest molecule, relative to energy minimum position in the cavity, is approximated by an harmonic oscillator. The advantage of this approach is that some frequencies of guest movements may interfere with the water lattice librational frequencies. As such we directly also get calculations for these effects, which are typically included as empirical correction, incorporated. For $\mathrm{CO}_{2}$ a comparison with a rigid lattice calculations and the harmonic oscillator approach reveal a destabilization effect of $1 \mathrm{~kJ} / \mathrm{mole}$ due to $\mathrm{CO}_{2}$ movements in the large cavity of structure I [12]:

$$
h_{k i}=e^{\beta\left[\mu_{k i}-\Delta g_{k i}\right]}
$$

$\beta$ is the inverse of the universal gas constant times temperature. $\mu_{k i}$ is the chemical potential of guest molecule $i$ in hydrate cavity of type $k$. At equilibrium this chemical potential is equal to the chemical potential for the same molecule in the phase it comes from during the hydrate formation. For Equation (1) that means gas, liquid or fluid as a separate phase. In a non-equilibrium situation the 
guest chemical potentials are adjusted for distances from equilibrium through a Taylor expansion, as discussed later. The free energies of inclusion (latter term in the exponent) are given in Table 3 below.

Table 3. Coefficients $a_{i}$ for free energy of guest type $j$ inclusion in cavity type $k ; \Delta g_{k j}=\sum_{i=1}^{i=6} a_{i}\left(\frac{T_{C_{j}}}{T}\right)^{(i-1)}$ with $T_{\mathrm{C}_{\mathrm{H}_{4}}}=190.56 \mathrm{~K}$ and $T_{\mathrm{CO}_{2}}=304.13 \mathrm{~K}$.

\begin{tabular}{cccccc}
\hline $\boldsymbol{i}$ & $\mathrm{CH}_{\mathbf{4}}$ & \multicolumn{2}{c}{$\mathbf{C O}_{\mathbf{2}}$ Large } & $\mathbf{C O}_{\mathbf{2}}$ Small \\
\hline & Large & Small & $\mathrm{T} \leq 283.14 \mathrm{~K}$ & $\mathrm{~T}>283.14 \mathrm{~K}$ & \\
1 & 17.97150 & -42.47683 & 41.52168 & -17.87093 & 0.19929 \\
2 & -23.44013 & 119.24124 & -41.96874 & -17.89249 & -28.28735 \\
3 & -161.81535 & -183.19565 & -70.72691 & 17.38136 & -11.94528 \\
4 & 45.20561 & 128.39252 & -11.81084 & -29.68940 & -2.66250 \\
5 & 36.67261 & -54.98784 & 16.73045 & -19.90321 & 3.85653 \\
6 & 138.00217 & -78.55671 & 21.91621 & 25.22112 & 3.21040 \\
\hline
\end{tabular}

Filling fractions in the various cavities, and mole-fractions in the hydrate are given by:

$$
\theta_{k i}=\frac{h_{k i}}{1+\sum_{j} h_{k i}}
$$

$\theta_{k i}$ is the filling fraction of component $i$ in cavity type $k$ :

$$
x_{i}^{H}=\frac{\theta_{\text {large }, i} v_{\text {large }}+\theta_{\text {small }, i} v_{\text {small }}}{1+\theta_{\text {large }, i} v_{\text {large }}+\theta_{\text {small }, i} v_{\text {small }}}
$$

$v$ is fraction of cavity per water. Corresponding mole-fraction water is then given by:

$$
x_{\mathrm{H}_{2} \mathrm{O}}^{\mathrm{H}}=1-\sum_{i} x_{i}^{H}
$$

The associated hydrate free energy is then:

$$
G^{(H)}=x_{H_{2} \mathrm{O}}^{H} \mu_{H_{2} \mathrm{O}}^{H}+\sum_{i} x_{i}^{H} \mu_{i}^{H}
$$

where $\mu$ is chemical potential. $\mathrm{H}_{2} \mathrm{O}$ subscripts denote water. $i$ are hydrate formers. $H$ superscripts denote hydrate. $x$ is mole-fraction in hydrate (superscript $H$ ) and $G$ is free energy.

Guest molecule i (in the case of this work either $\mathrm{CO}_{2}$ or $\mathrm{CH}_{4}$ ) chemical potential that enters Equations (4) and (8) at equilibrium is given by:

$$
\mu_{i}(T, P, \vec{y})=\mu_{i}^{\text {pure, idealgas }}(T, P, \vec{y})+R T \ln \left[y_{i} \phi_{i}(T, P, \vec{y})\right]
$$

where $y_{i}$ is the mole-fraction of component $i$ in the gas (or liquid or fluid) mixture. $\phi_{i}$ is the fugacity coefficient for component $i$. Chemical potential for a monoatomic model of methane in ideal gas state is trivial and analytical from statistical mechanics and the Boltzmann integral over translational momentums. For the rigid $\mathrm{CO}_{2}$ model there are two additional rotational contributions. The necessary moments of inertia are given in Table 2. The resulting ideal gas chemical potential ends up as trivial functions of temperature and density. The SRK [13] equation of state is utilized for calculating the fugacity coefficient, and also the density needed for the ideal gas chemical potential calculations. 


\subsection{Temperature and Pressure as Driving Forces for Heterogeneous Hydrate Formation on Water/Hydrate Former Interface}

With two components (one hydrate former and water) and three phases (water, hydrate former phase and hydrate), there are 12 independent thermodynamic variables, while the sum of conservation laws and conditions for thermodynamic equilibrium cover 11 variables. Hence, when both temperature and pressure are given locally in a reservoir, the system is over determined by 1 , and there is no unique equilibrium state. But a pressure temperature equilibrium curve will still represent asymptotic limits at which hydrate formation ends (or enter a modus on infinite time to continue) at that two-dimensional projection of the thermodynamic variables.

For the heterogeneous case we therefore first calculate the equilibrium curve. For pure $\mathrm{CH}_{4}$ or pure $\mathrm{CO}_{2}$, and a defined temperature, the chemical potential for the guest is given by Equation (9) for a variable pressure. This chemical potential enters Equation (4) along with the free energy of inclusion, which is a function of temperature only for small and large cavities. Equations (2) and (3) are solved for the same chemical potential of water in liquid state and hydrate given the equilibrium pressure. For completeness the free energies of inclusion are given in Table 3 below. Calculated equilibrium curves for $\mathrm{CH}_{4}$ and $\mathrm{CO}_{2}$ are compared to experimental data in Figure 2. It is important to keep in mind that the parameters for free energies of inclusion have been calculated from MD simulations with the procedures described in Kvamme and Tanaka [12] for temperatures up to $280 \mathrm{~K}^{\text {for }} \mathrm{CH}_{4}$. As such, all calculated results are predictions, and results for temperatures above $280 \mathrm{~K}$ are all extrapolations. For $\mathrm{CO}_{2}$, on the other hand, a system of nine unit cells of hydrate structure I was surrounded on all sides with a $3 \mathrm{~nm}$ thick layer of $\mathrm{CO}_{2}$ molecules. The system was run at $273.16 \mathrm{~K}$ and $283 \mathrm{~K}$ using SRK calculated densities in order to keep consistency with other calculations in this work that utilize the SRK equation of state. The system was then also run for $284 \mathrm{~K}$ and $290 \mathrm{~K}$, which are both in the dense $\mathrm{CO}_{2}$ region. The essential difference between the low temperature results and the high temperature results are the impact of the surrounding $\mathrm{CO}_{2}$ molecules on the water lattice vibrations. The hydrate water structure is dominated by the $75 \%$ large cavities and the small cavity does not even benefit much from any stabilization of $\mathrm{CO}_{2}$ due to the size and shape of the molecule. For the small cavities in structure I there is not statistical justification to distinguish between the effect of surround gas or liquid $\mathrm{CO}_{2}$.

The models for extending thermodynamic properties of water and fluid phases are discussed in detail elsewhere [19-21] and will not be repeated here due to space limitations.

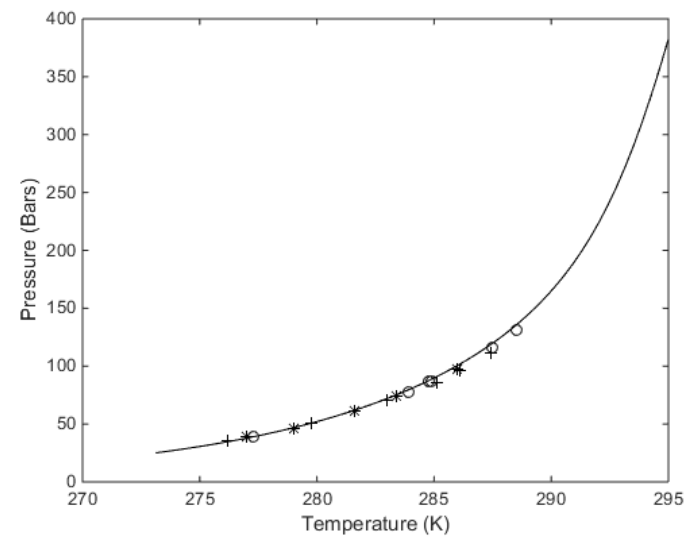

(a)

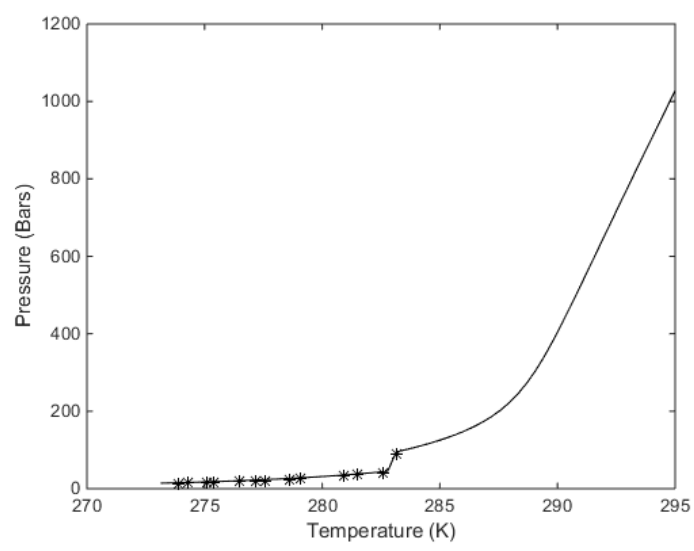

(b)

Figure 2. (a) Equilibrium curve for $\mathrm{CH}_{4}$ hydrate. Calculated values (solid) and experimental data from Bavoh et al. [22] $\left({ }^{*}\right)$, Tumba et al. [23] (+) and Sabil et al. [24] (o). (b) Calculated equilibrium curve for $\mathrm{CO}_{2}$ hydrate (solid) as compared to experimental data from Herri et.al. [25] (*). 
Two aspects regarding Figure $2 \mathrm{a}, \mathrm{b}$ are worth mentioning. The equilibrium curve for $\mathrm{CO}_{2}$ in Figure $2 \mathrm{~b}$ does not have a discontinuity but there is a rapid change in density related to a phase transition. This leads to a rapid decrease in fugacity coefficients and a corresponding higher pressure needed to reach hydrate equilibrium. Some researchers actually presents Figure $2 b$ as a continuous smooth curve without any rapid change. A second aspect is illustrated in Figure 2a. As can be seen, the equilibrium pressures for $\mathrm{CO}_{2}$ hydrate are higher than the equilibrium pressures for $\mathrm{CH}_{4}$ after the $\mathrm{CO}_{2}$ density increase. This is often wrongly interpreted as a higher stability for the $\mathrm{CH}_{4}$ hydrate above the temperature for the $\mathrm{CO}_{2}$ phase transition. Pressure and temperature are independent thermodynamic variables. Free energies are the corresponding thermodynamic responses for the level of thermodynamic stability. In Figure $2 \mathrm{~b}$ we plot free energies of $\mathrm{CH}_{4}$ and $\mathrm{CO}_{2}$ hydrate as function of temperature along the equilibrium pressures for the two types of hydrates.

Along the curves in Figure 2 the free energy changes in Equation (1) are trivially zero. Outside equilibrium all properties of fluids are continuous and can be calculated for any pressure and temperature. The necessary pressure correction for water chemical potential in Equation (2) is available from the molar volume of liquid water, which is almost constant and independent of temperature and pressure, time pressure minus equilibrium pressure for the actual temperature. Hydrate water chemical potential, on the other hand, is based on an equilibrium theory. The derivation [12] from the grand canonical ensemble in statistical mechanics leads to a Langmuir type of adsorption theory as expressed by Equation (3). For:

$$
G_{\text {Non-equilibrium }}^{H}(T, P, \vec{x})=\begin{gathered}
\left.G^{H, \mathrm{Eq} \cdot\left(T^{\mathrm{Eq} \cdot,}, P^{\mathrm{Eq} \cdot,}, \vec{x}\right.}{ }^{\mathrm{Eq} \cdot}\right)+\left.\sum_{r} \frac{\partial G^{H}}{\partial x_{r}}\right|_{P, T, x_{i \neq r}}\left(x_{r}-x_{r}^{\mathrm{Eq} \cdot}\right) \\
+\left.\frac{\partial G^{H}}{\partial P}\right|_{T, \vec{x}}\left(P-P^{\mathrm{Eq} \cdot)}+\left.\frac{\partial G^{H}}{\partial T}\right|_{P, \vec{x}}\left(T-T^{\mathrm{Eq} \cdot}\right)\right.
\end{gathered}
$$

we choose $T$ to be equal to an equilibrium temperature, for which equilibrium pressure and compositions are calculated according to the equation and discussion above. The correction for pressure change is related to the partial molar volumes of water and hydrate formers in hydrate. Water partial molar volume is given by the structure of the hydrate while the occupation volume of the guest molecules can be calculated from Monte Carlo simulations according to the procedures described by Kvamme and Lund [26] and Kvamme and Førridahl [27]. The calculated volumes are $164.2 \AA^{3} /$ molecule and $89.2 \AA^{3} /$ molecule for $\mathrm{CH}_{4}$ in large and small cavities, respectively. Corresponding values for $\mathrm{CO}_{2}$ are $135.6 \AA^{3} /$ molecule and $76.9 \AA^{3} /$ molecule for large and small cavities, respectively. The value for $\mathrm{CO}_{2}$ in small cavities is not practically interesting since the filling fractions of $\mathrm{CO}_{2}$ in small cavities is practically zero.

Classical nucleation theory (CNT) for a spherical hydrate particle can be written as:

$$
J=J_{0} e^{-\beta \Delta G^{T o t a l}}
$$

where $J_{0}$ is the mass transport flux supplying the hydrate growth. The phase transition in Equation (1) it will be the supply of $\mathrm{CH}_{4}$ or $\mathrm{CO}_{2}$ across an interface of gradually more structured water towards the hydrate core, as discussed in Kvamme et al. [19-21]. The units of $J_{0}$ will be moles $/ \mathrm{m}^{2} \mathrm{~s}$ for heterogeneous hydrate formation on the growing surface area of the hydrate crystal. $\beta$ is the inverse of the gas constant times temperature and $\Delta G^{\text {Total }}$ is the molar free energy change of the phase transition. This molar free energy consists of two contributions (Equation (1) with Equation (10)) to correct for hydrate properties outside of equilibrium which are the free energy benefit of the phase transition and the second contribution is the penalty related to the work of pushing aside old phases. Even for a hydrate forming on the gas/water interface any hydrate core below critical size will be covered by water also on the side facing the gas due to capillary forces. Molar densities of liquid water and hydrate are reasonably close. It is therefore a fair approximation to multiply the molar free energy of the phase transition with molar density of hydrate times the volume of hydrate core. The penalty of the push 
work is the interface free energy times the surface area of the hydrate crystal. The total free energy change in extensive formulation (underlines indicate Joule units):

$$
\Delta \underline{G}^{\text {Total }}=\Delta \underline{G}^{\text {Phasetransition }}+\Delta \underline{G}^{\text {Pushwork }}
$$

The simplest possible geometry of a crystal is a sphere and for a core radius $R$ the result is:

$$
\Delta \underline{G}^{\text {Total }}=\frac{4}{3} \pi R^{3} \rho_{N}^{H} \Delta G^{\text {Phasetransition }}+4 \pi R^{2} \gamma
$$

where $\rho_{N}^{H}$ is the molar density of the hydrate and $\gamma$ is the interface free energy between the hydrate and the surrounding phase. There is no reliable value for interface free energy between hydrate and liquid water since the measurement of such a property is extremely difficult. We have not found any value in the open literature. Interface free energy between liquid water and ice is available [28] and the reported value is $29.1 \mathrm{~mJ} / \mathrm{m}^{2}$. We have used this value as an approximation for interface free energy between liquid water and hydrate in the last term of Equation (13).

Differentiation of (13) with respect to $R$ gives the solution for maximum free energy radius (the critical core size):

$$
R^{*}=-\frac{2 \gamma}{\rho_{N}^{H} \Delta G^{\text {Phasetransition }}}
$$

Superscript * denotes critical nuclei radius. Calculated critical radii for $\mathrm{CH}_{4}$ hydrate at two different temperatures are given in Figure 3a. The associated nucleation times are based on integration of Fick's law:

$$
t(R)-t(o)=\int_{C_{\mathrm{CH}_{4}}(R=0)}^{C_{\mathrm{CH}_{4}}(R=12)} \frac{\partial C_{\mathrm{CH}_{4}}(z)}{\left[-D_{\mathrm{CH}_{4}}(z) \frac{\partial^{2} C_{\mathrm{CH}_{4}}(z)}{\partial z^{2}}\right]}
$$

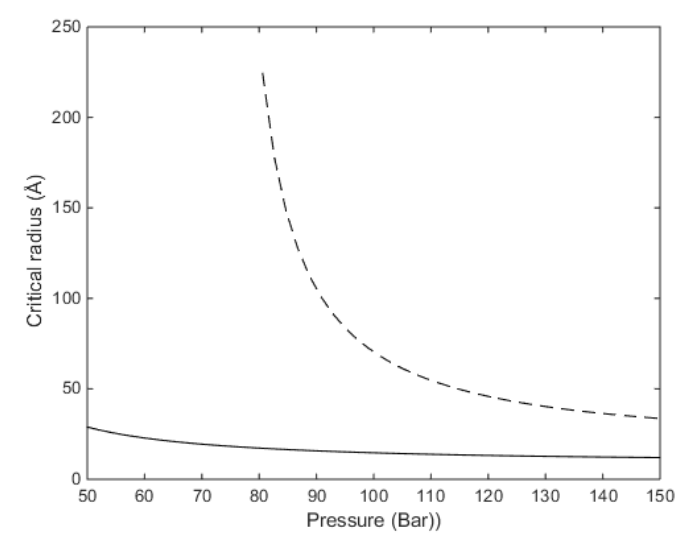

(a)

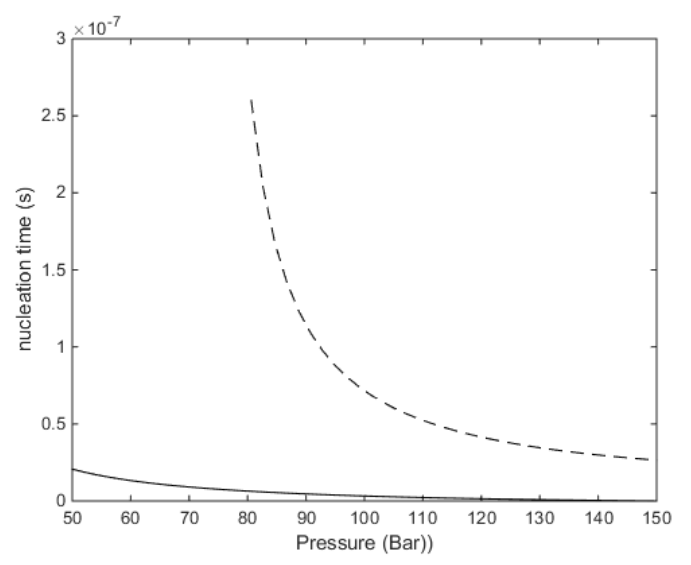

(b)

Figure 3. (a) Critical radius for $\mathrm{CH}_{4}$ hydrate as function of pressure for two different temperatures. Solid curve is for $273.16 \mathrm{~K}$ and dashed curve is for $283.16 \mathrm{~K}$. (b) Nucleation times for $\mathrm{CH}_{4}$ hydrate as function of pressure for $273.16 \mathrm{~K}$ (solid) and $283.16 \mathrm{~K}$ (dashed).

The concentration profiles for $\mathrm{CH}_{4}$ as a function of distance from the liquid side of the interface $(z=0 \AA)$ to the hydrate side of the interface $(z=12 \AA)$ is available from Kvamme [19,20] and Kvamme et al. [21]. The diffusivity coefficient profile for $\mathrm{CH}_{4}$ is assumed to be the same as for $\mathrm{CO}_{2}$ since the diffusion of $\mathrm{CH}_{4}$ and $\mathrm{CO}_{2}$ through the liquid/water interface is dominated by the gradually increased 
structure of water towards the hydrate side of the interface. The profile is given by Figure $8 \mathrm{a}$ in Kvamme [19] and fitted to Equation (16) with the parameters in Table 4 below.

$$
\left[\frac{D(z)_{j}}{D_{\text {liquid }, j}}\right]=9.5 \cdot 10^{-\sum_{i=1}^{9} a_{i}\left(a \tan \left[\left(0.5 z \frac{\pi}{2}\right) / 12\right]\right)^{i-1}}
$$

Table 4. Parameters for Equation (16).

\begin{tabular}{cccccc}
\hline $\boldsymbol{i}$ & Parameter & $\boldsymbol{i}$ & Parameter & $\boldsymbol{I}$ & Parameter \\
\hline 1 & 0.979242 & 4 & 171.673 & 7 & -9649.96 \\
2 & 15.5427 & 5 & 6.76975 & 8 & $14,779.7$ \\
3 & -88.5112 & 6 & 1939.55 & 9 & -7496.15 \\
\hline
\end{tabular}

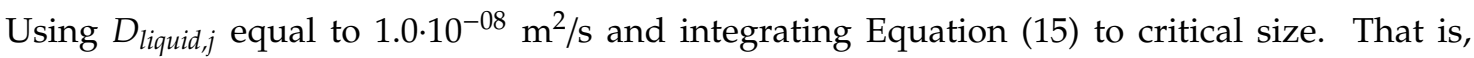
for every supply of hydrate-former needed to grow a hydrate core, the transport has to cross the interface thickness at the mass transport penalty given by Equation (16). The number of transported molecules is then recalculated to provide a corresponding radius added to the core size. This latter recalculation involves the calculated filling fraction and the corresponding volume of hydrate water. With reference to the equilibrium curve in Figure 2a note that the equilibrium pressure for $283.16 \mathrm{~K}$ is around 80 bars and that is the reason for the exponential increase in critical size when the pressure approaches 80 bar. As expected, there is a substantial increase in nucleation time between these two temperatures. At $273.16 \mathrm{~K}$ and 150 bar the calculated critical radius is $12.0 \AA$ and nucleation time is essentially instantaneous (less than one ns). Calculated critical radius at $283.16 \mathrm{~K}$ and 150 bars is $33.6 \AA$, and nucleation time is $26.5 \mathrm{~ns}$.

For transport of $\mathrm{CH}_{4}$ through the hydrate, in order to continue the growth of the film, it is now assumed that the diffusivity coefficient, and associated diffusion rate at the hydrate side of the interface, is equal to a stationary transport through the hydrate. This rate is expected to be slightly higher than regular diffusion through a block of hydrate without dynamics of couplings to heat transport and dynamic situations of partial local dissociation and reformation. See Kvamme et al. [21] for a brief summary of reported diffusivities of hydrate-formers through hydrate. In summary the diffusivities range from $10^{-15} \mathrm{~m}^{2} / \mathrm{s}$ to $10^{-17} \mathrm{~m}^{2} / \mathrm{s}$. Quite a number of the studies are based on Monte Carlo studies of "cavity jumping" and rarely reflect any mechanism for how guest molecules are actually able to move around in the hydrate structure. Based on our MD studies [12] the mechanism seems more like a temporary destabilization of water hydrogen bonding structures between filled cavities and empty neighbor cavities. Nevertheless, more detailed studies are needed to verify these observations in a scientifically satisfactory manner. For our purpose in the context of this work we then might expect diffusivity coefficients which are higher than the range indicated above due to the couplings with heat transport dynamics rapid local dissociation/refreezing effects. The heat transport dynamics is implicitly coupled through the relationship:

$$
\frac{\partial\left[\frac{\Delta G^{\text {Total }}}{R T}\right]_{P, N}}{\partial T}=-\left[\frac{\Delta H^{\text {Total }}}{R T^{2}}\right]
$$

which then connects Equations (12), (13) and (1) for any hydrate core since the number of moles in the actual radius of the core is simply the volume of the core times the molar density of the hydrate core. In the simple calculations below we disregard effects of heat transport dynamics. Based on our earlier calculations [15-18], and also in accordance with other sources in the literature, the heat transport rate through liquid water is 2-3 times faster than the corresponding mass transport rate. This ratio will be orders of magnitude higher for transport through hydrate. In accordance with this we expect that the mass transport rate is only affected by heat transport due to fast local phase transitions. 
Within the focus of this work we simply examine a couple of values for $D_{l i q}$ in (16) and plot the time needed to reach $1 \mathrm{~mm}$ hydrate film thickness. In Figure 4 we plot results for $D_{l i q}=5 \cdot 10^{-08} \mathrm{~m}^{2} / \mathrm{s}$ in Equation (16) and the condition of temperature and pressure equal to that used in a magnetic resonance imaging experiment conducted at the ConocoPhillips research laboratory in Bartlesville (OK, USA). The experiment was conducted at a temperature of $276.25 \mathrm{~K}$ and 83 bars with initial equal volumes of liquid water and $\mathrm{CH}_{4}$. See Kvamme et al. [29] for more details on the experiment. The container was made of plastic and as such was methane-wetting.

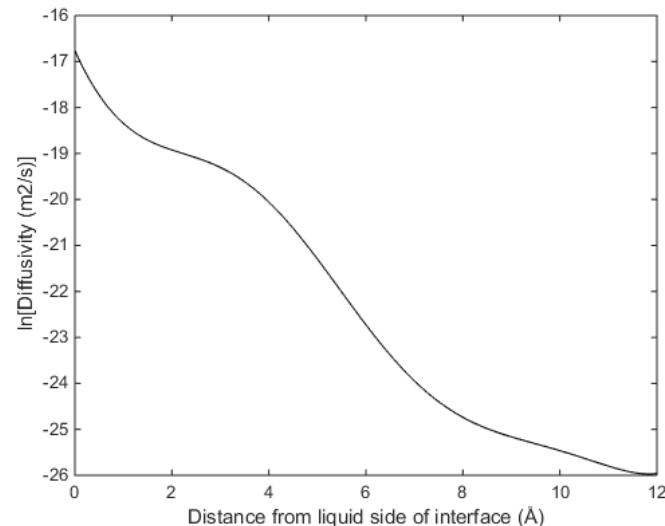

(a)

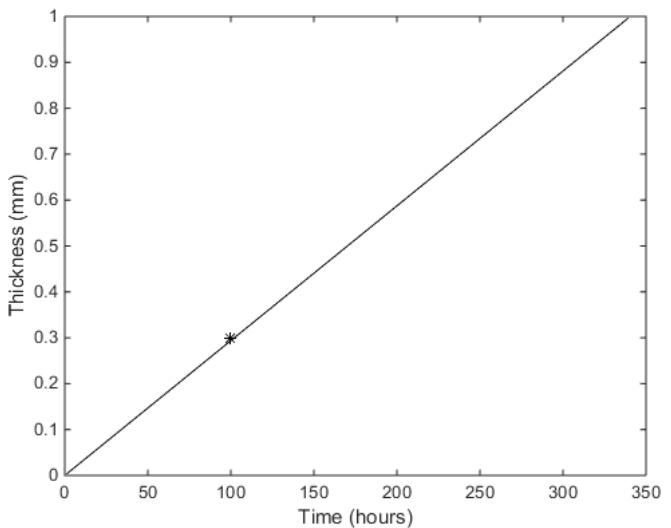

(b)

Figure 4. (a) Diffusivity profile for $D_{\text {liq }}=5 \cdot 10^{-08} \mathrm{~m}^{2} / \mathrm{s}$ in Equation (16) as applied for $\mathrm{CH}_{4}$ hydrate. (b) Calculated hydrate film thickness as function of time (solid) and experimental observation from Magnetic Resonance Imaging (MRI) experiment $[29,30]$ for $\mathrm{CH}_{4}$ hydrate based on a resolution of 300 micron.

Nucleation studies for $\mathrm{CO}_{2}$ have been published in a recent paper [19] and in order to save space we limit ourselves to estimates of growth as illustrated in Figure 5.

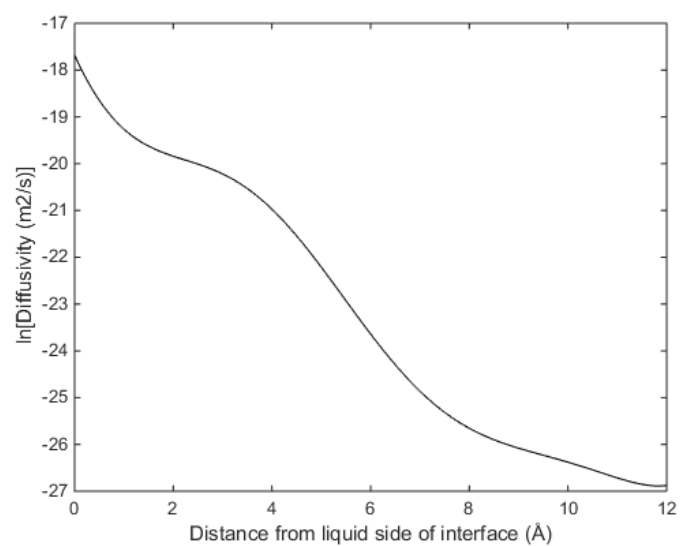

(a)

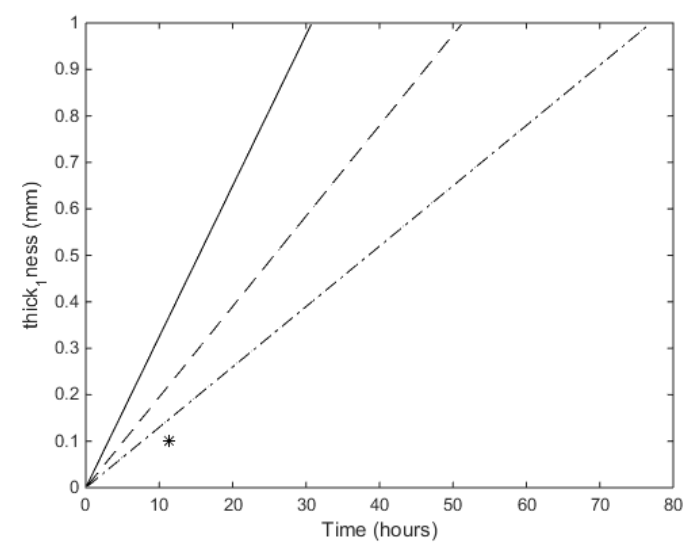

(b)

Figure 5. (a) Diffusivity profile for $D_{\text {liq }}=2 \cdot 10^{-08} \mathrm{~m}^{2} / \mathrm{s}$ in Equation (16) for $\mathrm{CO}_{2}$ hydrate. (b) Calculated hydrate film thickness as function of time for $D_{l i q}=5 \cdot 10^{-08} \mathrm{~m}^{2} / \mathrm{s}$ (solid), $D_{l i q}=3 \cdot 10^{-08} \mathrm{~m}^{2} / \mathrm{s}$ (dashed) and $D_{\text {liq }}=2 \cdot 10^{-08} \mathrm{~m}^{2} / \mathrm{s}$ (dash-dot). The experimental point $\left(^{*}\right)$ is rather uncertain and based on visual reading of a picture in Uchida et al. [31] for a water droplet exposed to $\mathrm{CO}_{2}$ under hydrate forming conditions.

Based on the methods of Kvamme and Tanaka [12] it is easy to see that water molecules between a filled cavity and a neighboring empty cavity have higher librational movements and hydrogen bonding structures can temporarily break and let guest molecules move to the empty cavity. For $\mathrm{CH}_{4}$ this can happen for all cavities while for the larger $\mathrm{CO}_{2}$ only large cavity neighbors can participate 
in such transports. As such it is reasonable that the diffusivity coefficient for $\mathrm{CO}_{2}$, through hydrate, is lower than the corresponding values for $\mathrm{CH}_{4}$. And just as macroscopic heat transport is orders of magnitude faster than mass transport so is the local molecular heat transport involved in breaking and reforming hydrogen water hydrogen bonds during migration of a guest molecule between cavities.

The mechanical strength of hydrate films in a pore depends on the cross section area, thickness and strength of connection to the mineral surfaces. As discussed in several papers, for instance [32,33] and papers referenced therein, hydrate can never touch the surface of minerals. From a thermodynamic point of view this can easily be verified in calculated and experimental structures of water. The density of the first adsorbed water layer on minerals such as calcite, hematite, and kaolinite is on the order of three times the density of liquid water. The associated chemical potential is very low and far lower than is ever possible for water in hydrate. Even the average chemical potential of adsorbed water as calculated over the first five layers of water adsorbed on Hematite may be as low as $3.4 \mathrm{~kJ} / \mathrm{mole}$ lower than liquid water [32]. The reason is the strong Coulombic interactions between water partial charges and charges on atoms in the mineral surfaces. For the same reason it is also easy to see that the regular distribution of partial charges on water hydrogens and oxygens in a hydrate crystal can never favorably match the distribution of positive and negative charges on the mineral surfaces.

What we have presented above provides a tool for analyzing how rapidly the hydrate film will grow, and for specific porosity and minerals, when and at what frequency we need to shock the system in order to break these hydrate films during the formation of hydrate in a specific sediment model (or real sediment from coring) in a laboratory set-up. For this purpose we need a higher resolution time scale of the growth, and in Figure 6 we plot the times needed to reach $100 \mathrm{~nm}$ and 10 micron $(10,000 \mathrm{~nm})$.

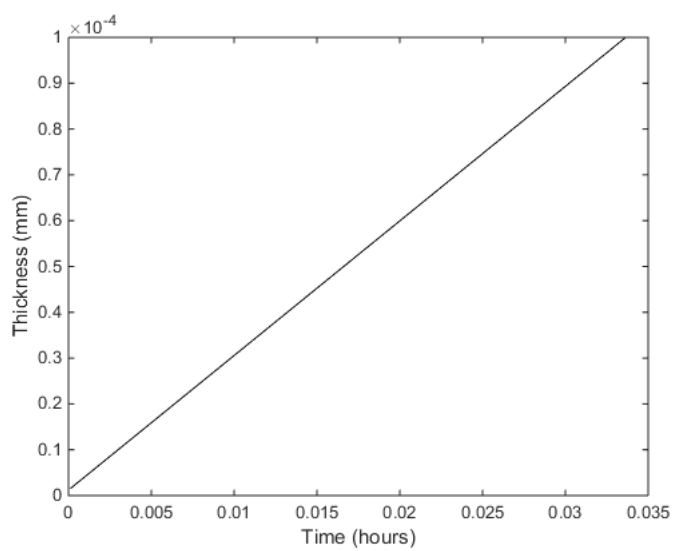

(a)

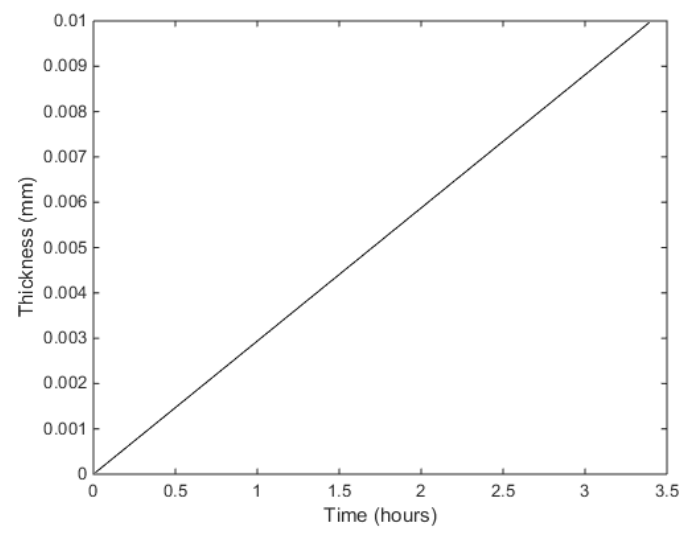

(b)

Figure 6. (a) Time to grow $100 \mathrm{~nm} \mathrm{CH}_{4}$ hydrate film. (b) Time to grow 10 micron hydrate film.

As discussed above it is a straightforward mechanical calculation to determine the magnitude of a mechanical pulse. If $100 \mathrm{~nm}$ is an acceptable thickness then the frequency of a mechanical shock pulse needs to be on the average $2 \mathrm{~min}$. Depending on the laboratory set-up this pulse can be generated by sound, mechanical shaking of the sediments section etc. The important thing is that the sediments section is kept in place relative to circulation of fluids and that the mechanical pulse that is used to break the hydrate films is moderate according to the forces needed to break the hydrate films. The necessary force needed is sensitive to many factor like for instance pore size, geochemical issues (mineral types and salinity) as well as temperature and pressure. Calculations of necessary forces to break the hydrate films using mechanical pulses are therefore too case specific to discuss in a more general paper like this.

In the Ignik Sikumi test on hydrate production $[8,9,11]$ large amounts of $\mathrm{N}_{2}$ were added and the thermodynamic driving force for creating a new $\mathrm{CO}_{2}$ hydrate was practically lost [9]. Instead of mechanically, breaking the hydrate films with efficient surfactants can keep the water/ $/ \mathrm{O}_{2}$ interface free of blocking hydrate and permit for more continuous hydrate formation from the injected $\mathrm{CO}_{2}$. 
Even methanol has surfactant properties but is too solvable in water to be interesting. And methanol is of course poisonous and not desirable to use. But some general insight can be found from a recent study [21].

\subsection{Residual Thermodynamic Modeling of Hydrate Formation from Water and Dissolved Hydrate Former in Water}

Hydrate can nucleate and grow from dissolved hydrate formers as discussed in a number of papers $[9,10,14-16,18,19,21,29,30]$ :

$$
\Delta G^{\left(H_{2}\right)}=\left[\begin{array}{c}
x_{\mathrm{H}_{2} \mathrm{O}}^{\mathrm{H}_{2}}\left(\mu_{\mathrm{H}_{2} \mathrm{O}}^{\mathrm{H}_{2}}\left(T, P, \vec{x}^{\mathrm{H}_{2}}\right)-\mu_{\mathrm{H}_{2} \mathrm{O}}^{\text {water }}(T, P, \vec{x})\right) \\
+\sum_{j} x_{j}^{\mathrm{H}_{2}}\left(\mu_{j}^{\mathrm{H}_{2}}\left(T, P, \vec{x}^{\mathrm{H}_{2}}\right)-\mu_{j}^{\text {water }}(T, P, \vec{x})\right)
\end{array}\right]
$$

Chemical potential for water as solvent for $\mathrm{CH}_{4}$ is not affected significantly by the very low concentrations of $\mathrm{CH}_{4}$. For $\mathrm{CO}_{2}$ dissolved in water the approximation in Equation (2) is considered to be good enough for the purpose of this work. Models for chemical potential of the hydrate former, which appear in the last term of Equation (18) are discussed in more detail in [19-21] and will not be repeated here. These chemical potentials also enter the canonical partition function for guest molecules in the two types of cavities through Equation (4). The actual film thickness that can be added through this route is limited for $\mathrm{CH}_{4}$ and significant for $\mathrm{CO}_{2}$.

There are several implications of the calculations illustrated in Figure 7. Dissociation of hydrate leads to a combination of gas bubbles and supersaturation of hydrate former in the surrounding water. This can then in turn lead to reformation of hydrate from dissolved hydrate former in concentration ranges between the blue and the black curve. If water surrounding the hydrate is diluted below the black curve then hydrate will dissociate. Also keep in mind that every unique concentration of hydrate former in between the blue and black curves will lead to a unique hydrate composition due to the chemical potential dependency of hydrate former as a function of concentration. Mathematically this means that an infinite number of different hydrates are possible. Stability will of course vary substantially.

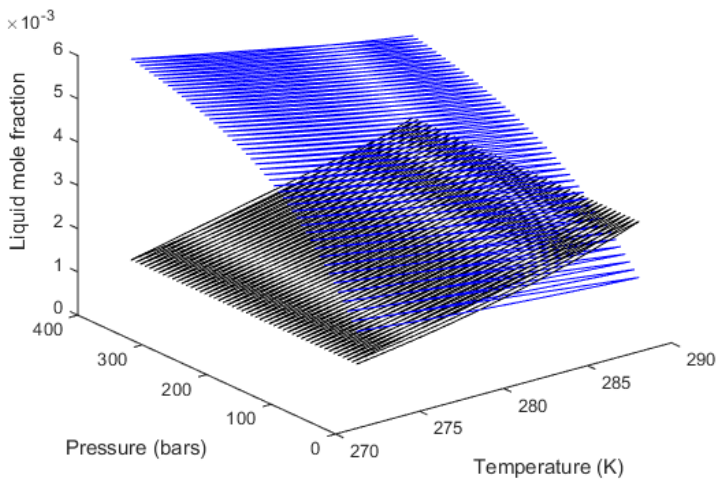

(a)

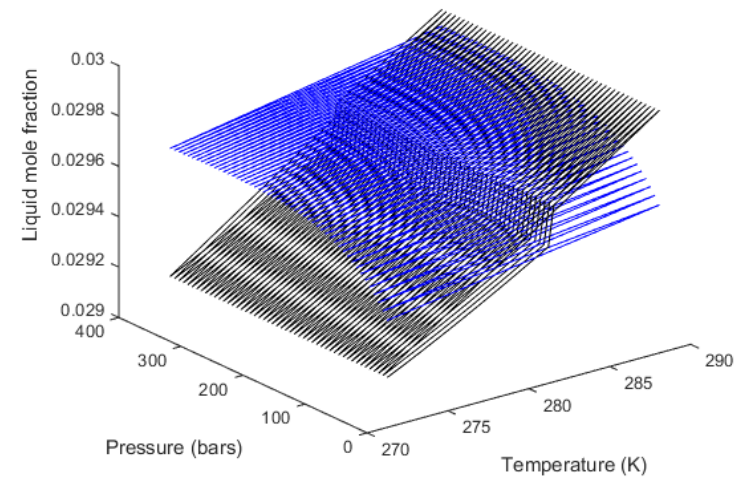

(b)

Figure 7. (a) Solubility of $\mathrm{CH}_{4}$ in liquid water (blue) and lower limit of hydrate stability (black). (b) Solubility of $\mathrm{CO}_{2}$ in water (blue) and lower limit of hydrate stability. Hydrate can grow from solution for concentration below the blue and black contours. Concentrations of hydrate formers in surrounding water less than the black contours lead to hydrate dissociation. Possible concentration of hydrate formers in water above the blue contours lead to degassing from water solution. Examples of the free energies of hydrates from water and $\mathrm{CH}_{4}$, and water and $\mathrm{CO}_{2}$ are given in Figure $10 \mathrm{~b}$ as function of temperature and pressure. Free energies for hydrates formed homogeneously from solution are different but the relative picture between $\mathrm{CH}_{4}$ hydrate and $\mathrm{CO}_{2}$ hydrates are similar. 
Figure 8 illustrates a bit more clearly the regions for which it is not possible to grow hydrate from dissolved hydrate formers in water, i.e., regions for which the blue curves are lower in free energy. As expected, the differences in hydrate free energies between $\mathrm{CH}_{4}$ hydrate formed from solution is slightly less stable than $\mathrm{CO}_{2}$ hydrate formed from solution. But the differences are hardly significant compared to the corresponding differences in free energies formed heterogeneously from gas (or fluid) hydrate former phase and liquid water.

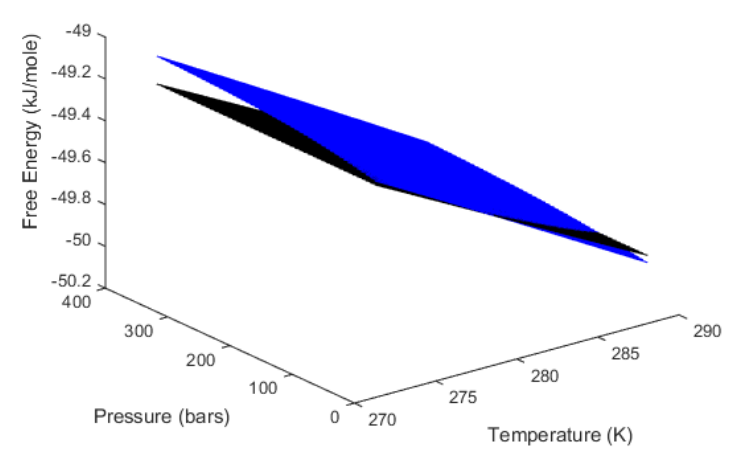

(a)

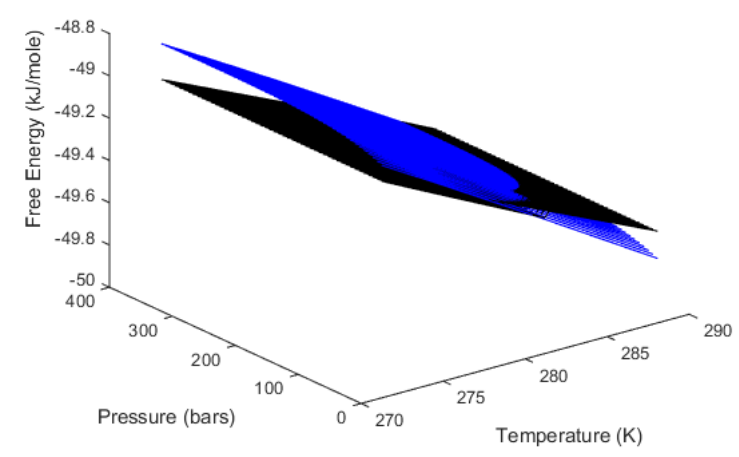

(b)

Figure 8. (a) Free energy of aqueous solution of $\mathrm{CH}_{4}$ (blue) and free energy of $\mathrm{CH}_{4}$ hydrate at stability limit towards liquid water (black). (b) Free energy of aqueous solution of $\mathrm{CO}_{2}$ (blue) and free energy of $\mathrm{CO}_{2}$ hydrate at stability limit towards liquid water (black). These contours illustrate the thermodynamic driving forces for hydrate formation from solution. The black contours are not the free energy of the hydrates but the free energy benefits for creating hydrate for the specific concentrations of hydrate formers in water as given in Figure 7.

\subsection{Hydrate Nucleation from Primary and Secondary Adsorption of Hydrate Formers on Mineral Surfaces}

$\mathrm{CH}_{4}$ is non-polar and cannot adsorb directly on charged mineral surfaces in competition with water, but $\mathrm{CH}_{4}$ molecules can get trapped in structured water as illustrated in some recent MSc studies at the University of Bergen [34]. These studies indicates that methane gets dynamically trapped in structured water-typically from the third minimum in the water density as a function of distance from the calcite surface. As long there is a separate methane phase outside of the water layer in contact with the calcite a methane/water region, or phase, exists inside the water. Average water/methane distances in this separate phase are close to the characteristics of a small hydrate cavity. But the dynamics of the structure makes it hard to evaluate associated chemical potentials for methane with sufficient confidence. Work is in progress to overcome these challenges. Some illustrative animations from the MD simulations are available from the first author of the current work.

Direct adsorption is possible for polar and slightly polar hydrate formers like $\mathrm{H}_{2} \mathrm{~S}$, which has a significant dipole moment and adsorbs well on the same type of minerals as water due to similarities in molecular structures. Although we do have a variety of chemical potentials for different interaction models for $\mathrm{H}_{2} \mathrm{~S}$ the limitation is that the results cannot be evaluated. Chemical potentials of adsorbed molecules cannot be measured directly but the density profiles of adsorbed molecules can be derived from measured structure factors. One of our examples for adsorbed $\mathrm{CO}_{2}$ on Calcite [33] is illustrated in Figure 9 below. The finer details of the molecular simulations are too extensive in the context of this paper so the reader is directed to the original work [33], which is available for free download or can be provided by the first author of this paper. In the context of this paper we only need the calculated value for chemical potential as an example. The average value is of course sensitive to temperature and we can only solve for the hydrate stability pressure for this particular temperature, which is 17.0 bar when liquid water chemical potential is used for the water. This can be compared to a stability limit pressure of 15.7 bars for the same temperature and using $\mathrm{CO}_{2}$ from gas. This is work in progress and more detailed studies of the chemical potentials of $\mathrm{CO}_{2}$ and water that actually makes the nuclei is needed. 

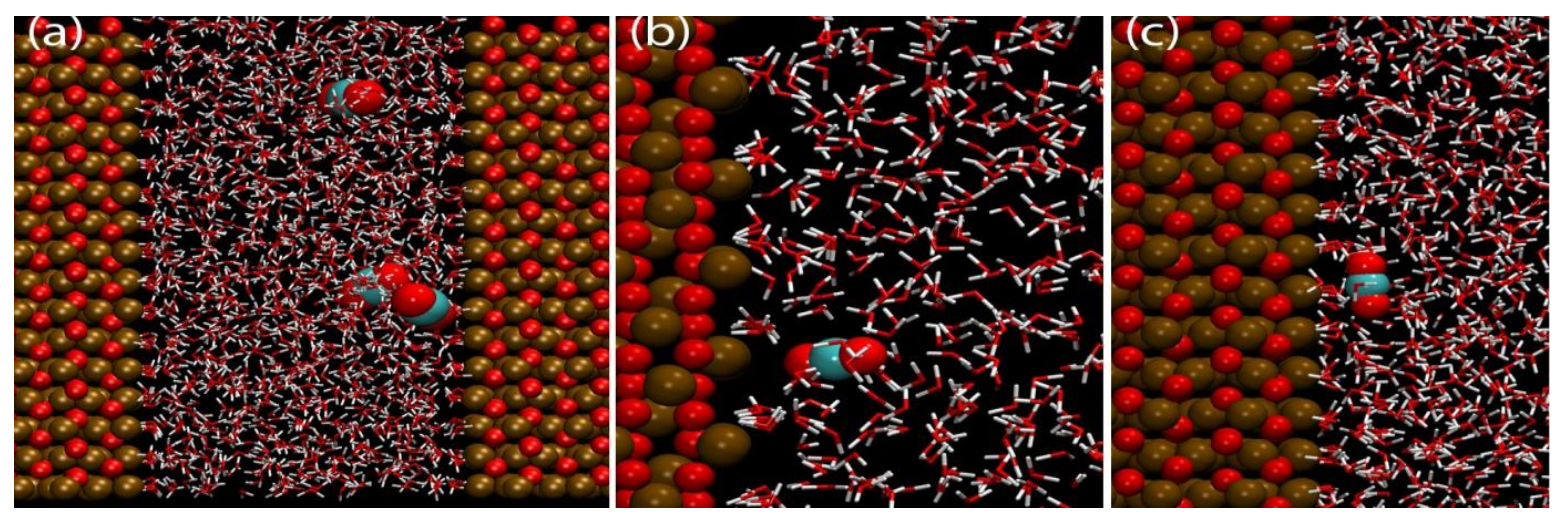

Figure 9. Snapshots of various configurations of trapped $(\mathbf{b}, \mathbf{c})$ and directly adsorbed $\mathrm{CO}_{2}$ on a Calcite surface at $274 \mathrm{~K}$. Red on calcite is oxygens and brown is calcium, but upscale relative to size of water. $\mathrm{CO}_{2}$ is upscale, with red for oxygens and cyan for carbon. Water molecules have white hydrogens and red oxygens. The average value of $\mathrm{CO}_{2}$ chemical potential is $-39.21 \mathrm{~kJ} / \mathrm{mole}$.

\section{Discussion}

Hydrates in sediments can form from many different phases. The most important routes to hydrates are, however, initial nucleation on the interface between water and hydrate former phase and nucleation towards mineral surfaces. These two routes are very different in the sense that hydrate cannot touch mineral surfaces but will be able nucleate towards mineral surfaces and then detach. Nucleation of hydrate on the interface between hydrate former phase and water, on the other hand, can lead to a dramatic slow-down in growth due to mass transport limitations of hydrate formers through the hydrate film. Visual observation or other monitoring techniques will therefore often lead to incorrect interpretations of induction times as nucleation times.

The problem of hydrate films that slow down hydrate growth often leads to a typical misunderstanding that $\mathrm{CO}_{2}$ is not efficient for producing hydrates. The opposite might actually be the case with the right additives to the $\mathrm{CO}_{2}$, but this is the subject for a subsequent paper, although the papers [19-21] give some insights.

Another frequent misunderstanding is that methane hydrate is more stable than $\mathrm{CO}_{2}$ hydrate above a certain temperature, as illustrated in the combined Figure $2 \mathrm{a}, \mathrm{b}$ above and Figure $10 \mathrm{~b}$ below. Temperature and pressure are independent thermodynamic variables and the free energy is what determines phase stability and relative stability. Free energies of $\mathrm{CH}_{4}$ and $\mathrm{CO}_{2}$ hydrates along the equilibrium conditions are plotted in Figure 10b. There are consequences of these differences and this will be discussed further in a subsequent paper. 


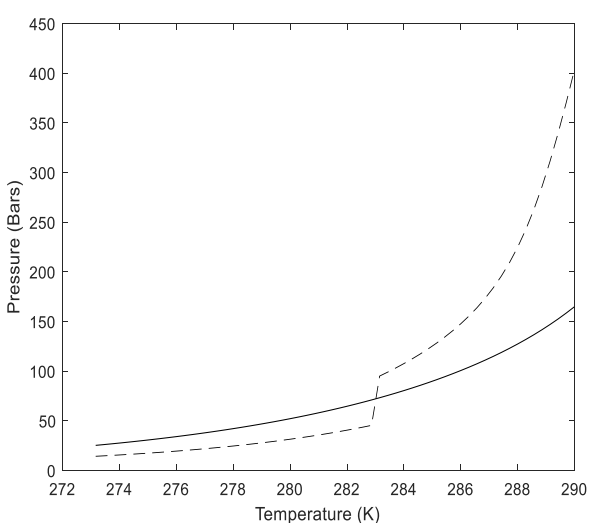

(a)

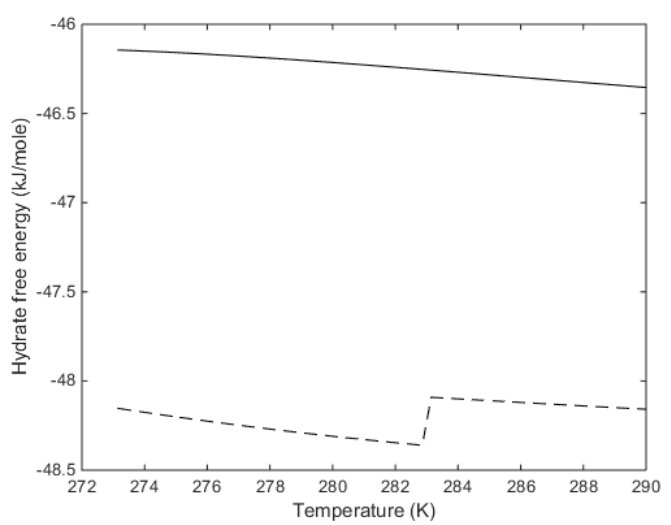

(b)

Figure 10. (a) Pressure temperature equilibrium curves for $\mathrm{CH}_{4}$ hydrate (solid) and $\mathrm{CO}_{2}$ hydrate (dash). (b) Free energies for hydrates of $\mathrm{CH}_{4}$ (solid) and $\mathrm{CO}_{2}$ (dash) hydrates along their equilibrium conditions of temperature and pressure.

Even if the diffusivity of hydrate formers through hydrate films is faster than is represented by diffusivity coefficients on the order of $10^{-15} \mathrm{~m}^{2} / \mathrm{s}$ or less due to local dissociation mechanisms, a solid state transition $[5,6]$ is highly unlikely for temperatures above freezing, as is also discussed elsewhere $[11,16,19,35,36]$. The thermodynamic driving force for such a transition would be the difference in free energy derived from Figure 10b. In such a system water is either hydrate or frozen water except in the mineral/water interface and the water hydrate interface, which are both nano scale in thickness. The only other exception is water trapped in small pores and unlikely to form hydrate due to mechanical strain in the hydrate lattice and a relatively large impact of mineral surfaces. The experiments at temperatures far below zero have limited value for relevant hydrate reservoirs since the solid state conversion is likely never going to play any role in reservoirs. Another confusion caused by these experiments is the inclusion of $\mathrm{CO}_{2}$ in small cavities. It is theoretically possible but not thermodynamically feasible at realistic reservoir temperatures above zero.

The only feasible formation concept is, therefore, that injected $\mathrm{CO}_{2}$ forms a new $\mathrm{CO}_{2}$ hydrate and that the released hydrate heat of formation dissociates $\mathrm{CH}_{4}$ hydrate. There is actually excess heat available for this process since the heat of formation of $\mathrm{CO}_{2}$ hydrate is higher than is needed to dissociate $\mathrm{CH}_{4}$ hydrate, as illustrated in Figure 11a above [19,20]. Adding large amounts of nitrogen in the $\mathrm{CO}_{2}$, or using fuel gas dominated by nitrogen is not a good solution, as discussed earlier in several papers, e.g., [9], and illustrated in Figure $11 \mathrm{~b}$ for 146 bar. At $276 \mathrm{~K}$ more than $30 \% \mathrm{CO}_{2}$ is needed in order to make new hydrate with water. At temperatures above slightly more than $286 \mathrm{~K}$ chemical potential for liquid water is also lower than chemical potential of water in hydrate from pure $\mathrm{CO}_{2}$ and water, which is also illustrated by the equilibrium curve in Figure 2b. A limited amount of nitrogen can be useful for increasing the permeability of the injection gas. And since nitrogen can enter the $25 \%$ small cavities of a structure I hydrate primarily stabilized by $\mathrm{CO}_{2}$, any addition of nitrogen reduces the thermodynamic driving force for making a new $\mathrm{CO}_{2}$ hydrate. Large amounts of $\mathrm{N}_{2}$ (or even air) will lead to dissociation of $\mathrm{CH}_{4}$ hydrate because the $\mathrm{N}_{2}$ phase (or air) is undersaturated with $\mathrm{CH}_{4}$ relative to the chemical potential of $\mathrm{CH}_{4}$ in the hydrate, and if the $\mathrm{N}_{2}$ (or air) is dry relative to water saturation with reference to water in hydrate that will be an additional driving force for $\mathrm{CH}_{4}$ hydrate dissociation. Figure 1 in the recent paper by Darnell et al. [37] is therefore wrong since the $\mathrm{N}_{2}$ hydrate stability limit curve (green curve) is not relevant for the actual processes. The $\mathrm{CO}_{2}$ hydrate curve, as well as the $\mathrm{CO}_{2}$ fluid curves is also wrong since $\mathrm{CO}_{2}$ goes through a phase transition. This has been discussed elsewhere in this work. See also Figure 2. See also Figures 10 and 11 which illustrate the need for a thermodynamic analysis rather than plots in independent thermodynamic variable $\mathrm{P}$ and $\mathrm{T}$. A simulation model without real phase transition analysis in terms of free energy based functions are therefore of limited value. Lack of heat transport analysis is also a limitation of this work. The free 
energy difference between $\mathrm{CH}_{4}$ in the hydrate and in the outside $\mathrm{N}_{2}$, as one example, will enter as the thermodynamic benefit but this driving force is implicitly coupled to mass-and heat-transport dynamics. See also Kvamme [19,20] and Kvamme et al. [21] for more details.

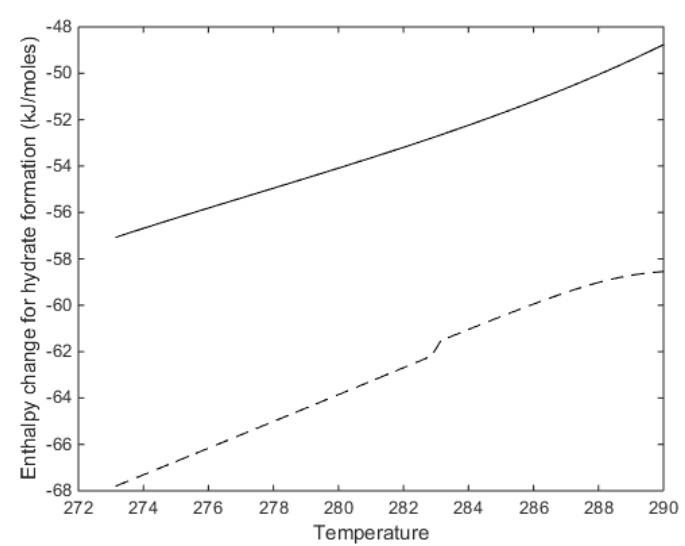

(a)

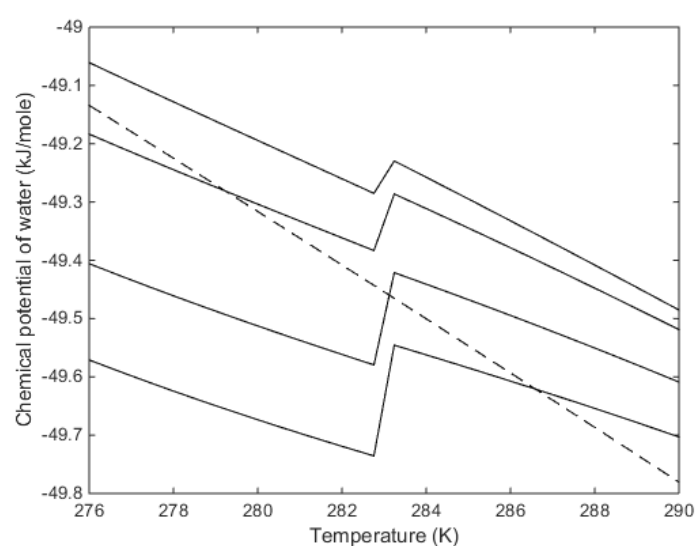

(b)

Figure 11. (a) Enthalpy of $\mathrm{CH}_{4}$ hydrate formation (solid) along the hydrate equilibrium curve and enthalpy of $\mathrm{CO}_{2}$ hydrate formation (dashed) along the hydrate equilibrium curve. (b) Chemical potential of liquid water (dashed) at 146 bar as function of temperature. Solid curves are chemical potentials for water in hydrates formed from $\mathrm{CO}_{2}$ and $\mathrm{N}_{2}$ mixtures at 146 bars. Lower solid curve is for pure $\mathrm{CO}_{2}$, next solid curve is for 70 mole per cent $\mathrm{CO}_{2}$, then 40 mole per cent $\mathrm{CO}_{2}$ and top is for 20 mole per cent $\mathrm{CO}_{2}$.

The key to efficient additives is illustrated in the paper by Kvamme et al. [21]. Small amounts of methanol in water will have a hydrate-activating effect due to its surfactant properties. First of all the concentration of methanol at the water/ $/ \mathrm{CH}_{4}$ interface will keep the interface open and free of blocking hydrate films. A second effect is increased transport rates for $\mathrm{CH}_{4}$ into water. The third effect is a higher solubility of $\mathrm{CH}_{4}$ in the water below the methanol concentrated layer. The hydrate activator effect of small amounts of methanol is well-known from industrial experience and the Tommeliten study [38]. Methanol is of course not a desirable additive since it will dissolve in water, and will eventually also disappear from the interface, but adding small surfactants to $\mathrm{CO}_{2}$ is a good approach. Large water/ $/ \mathrm{CO}_{2}$ surfactants, on the other hand, are not useful additives for enhancing the injection of $\mathrm{CO}_{2}$. Heavy surfactants on the order of molecular weights of some few thousand is like to cause problems of surfactant clogging and blocking of the flow pathways in between hydrate and mineral surfaces. Thermal breaking of hydrate films are also an alternative. The dynamics of hydrate film formation and growth are still useful tools together with energy balance for calculation of heating/cooling frequencies and necessary heat impulses for breaking desired film thickness.

\section{Conclusions}

Hydrates can nucleate from many phases. Except for cases of extremely small thermodynamic driving forces it is nano-scale phenomenon in both time and volume, as illustrated in this work using classical nucleation theory. The values for critical hydrate sizes obtained in this work are very much in accordance with earlier results that we have calculated from far more theoretically advanced approaches. Transport through hydrate films established through heterogeneous hydrate formation on the interface between liquid water and hydrate former phase is extremely slow. Simplified mass transport limitation models are able to verify the long induction times that are frequently observed in hydrate experiments. This type of information is critical since it can be used to design experimental equipment for efficient formation of hydrates in the laboratory. In particular it can be used to calculate the necessary frequencies for mechanical shock pulses for breaking mass transport-limiting hydrate films and ensure efficient conversion of water and hydrate-formers in the sediment pores. 
These calculations will also be useful if cycles of heating/cooling are used to break hydrate films and reform hydrate. The existence of these mass transport limiting films is also a critical issue in the use of $\mathrm{CO}_{2}$ for combined production of $\mathrm{CH}_{4}$ from hydrate and safe storage of $\mathrm{CO}_{2}$ in the form of hydrate. Adding nitrogen in small amounts increases gas permeability but it is absolutely critical that the amount of nitrogen be balanced so that there is still a significant driving force for creating a new $\mathrm{CO}_{2}$-dominated hydrate from the injection gas. Adding specially designed small surfactants will keep interfaces open and free of blocking hydrate films.

Author Contributions: All authors have been involved in Methodology, formal analysis and writing-review \& editing.

Funding: This research received no external funding

Conflicts of Interest: The authors declare no conflict of interest.

\section{References}

1. Dallimore, S.R.; Uchida, T.; Collett, T.S. Scientific Results from JAPEX/JNOC/GSC Mallik 2L-38 Gas Hydrate Research Well, Mackenzie Delta, Northwest Territories, Canada; Bulletin 544; Geological Survey of Canada: Ottawa, ON, Canada, 1999.

2. Hancock, S.H.; Collett, T.S.; Dallimore, S.R.; Satoh, T.; Inoue, T.; Huenges, E.; Henninges, J.; Weatherill, B. Overview of Thermal-Stimulation Production-Test Results for the JAPEX/JNOC/GSC et al. Mallik 5L38 Gas Hydrate Production Research Well; Bulletin 585; Geological Survey of Canada: Ottawa, ON, Canada, 2005.

3. Konno, Y. Oral Presentation. In Proceedings of the Nanotechnology and Nano-Geoscience in Oil and Gas Industry, Kyoto, Japan, 4-8 March 2014.

4. Tenma, N. Recent Status of Methane Hydrate R\&D Program in Japan. In Proceedings of the 11th International Methane Hydrate Research and Development, Corpus Christie, TX, USA, 5-8 December 2017.

5. Lee, H.; Seo, Y.; Seo, Y.-T.; Moudrakovski, I.L.; Ripmeester, J.A. Recovering methane from solid methane hydrate with carbon dioxide. Angew. Chem. Int. Ed. 2003, 42, 5048-5051. [CrossRef] [PubMed]

6. Falenty, A.; Genov, G.; Hansen, T.C.; Kuhs, W.F.; Salamatin, A.N. Kinetics of $\mathrm{CO}_{2}$-hydrate formation from water frost at low temperatures: Experimental results and theoretical model. J. Phys. Chem. C 2010, 115, 4022-4032. [CrossRef]

7. Kuznetsova, T.; Kvamme, B.; Morrissey, K. An alternative for carbon dioxide emission mitigation: In situ methane hydrate conversion. AIP Conf. Proc. 2012, 1504, 772-775.

8. Schoderbek, D.; Farrell, H.; Hester, K.; Howard, J.; Raterman, K.; Silpngarmlert, S.; Lloyd Martin, K.; Smith, B.; Klein, P. ConocoPhillips Gas Hydrate Production Test Final Technical Report (1 October 2008-30 June 2013); ConocoPhillips Company for United States Department of Energy National Energy Technology Laboratory: Houston, TX, USA, 2013.

9. Kvamme, B. Thermodynamic limitations of the $\mathrm{CO}_{2} / \mathrm{N}_{2}$ mixture injected into $\mathrm{CH}_{4}$ hydrate in the Ignik Sikumi field trial. J. Chem. Eng. Data 2016, 61, 1280-1295. [CrossRef]

10. Baig, K. Nano to Micro Scale Modeling of Hydrate Phase Transition Kinetics. Ph.D. Thesis, University of Bergen, Bergen, Norway, 2017.

11. Baig, K.; Kvamme, B.; Kuznetsova, T.; Bauman, J. The impact of water/hydrate film thickness on the kinetic rate of mixed hydrate formation during $\mathrm{CO}_{2}$ injection into $\mathrm{CH}_{4}$ hydrate. AIChE J. 2015, 61, 3944-3957.

12. Kvamme, B.; Tanaka, H. Thermodynamic stability of hydrates for ethane, ethylene, and carbon dioxide. J. Phys. Chem. 1995, 99, 7114-7119. [CrossRef]

13. Soave, G. Equilibrium constants from a modified Redlich-Kwong equation of state. Chem. Eng. Sci. 1972, 27, 1197-1203. [CrossRef]

14. Kvamme, B.; Graue, A.; Aspenes, E.; Kuznetsova, T.; Gránásy, L.; Tóth, G.; Pusztai, T.; Tegze, G. Kinetics of solid hydrate formation by carbon dioxide: Phase field theory of hydrate nucleation and magnetic resonance imaging. Phys. Chem. Chem. Phys. 2004, 6, 2327-2334. [CrossRef]

15. Tegze, G.; Pusztai, T.; Tóth, G.; Gránásy, L. Multiscale approach to $\mathrm{CO}_{2}$ hydrate formation in aqueous solution: Phase field theory and molecular dynamics. Nucleation and growth. J. Chem. Phys. 2006, 124, 234710. [CrossRef]

16. Kivelä, P.-H.; Baig, K.; Qasim, M.; Kvamme, B. Phase field theory modeling of methane fluxes from exposed natural gas hydrate reservoirs. AIP Conf. Proc. 2012, 1504, 351-363. 
17. Qasim, M. Microscale Modeling of Natural Gas Hydrates in Reservoirs. Ph.D. Thesis, University of Bergen, Bergen, Norway, 2012.

18. Svandal, A. Modeling Hydrate Phase Transitions Using Mean-Field Approaches. Ph.D. Thesis, University of Bergen, Bergen, Norway, 2006.

19. Kvamme, B. Environmentally friendly production of methane from natural gas hydrate using carbon dioxide. Sustainability 2019, 11, 1964.

20. Kvamme, B. Enthalpies of hydrate formation from hydrate formers dissolved in water. Energies 2019, $12,1039$. [CrossRef]

21. Kvamme, B.; Selvåg, J.; Aromada, S.A.; Saeidi, N.; Kuznetsova, T. Methanol as hydrate inhibitor and hydrate activator. Phys. Chem. Chem. Phys. 2018, 20, 21968-21987. [CrossRef] [PubMed]

22. Bavoh, C.B.; Partoon, B.; Laland, B.; Keong, L.K. Methane hydrate liquid-vapour-equilibrium phase condition measurements in the presence of natural amino acids. J. Nat. Gas Sci. Eng. 2017, 37, 425-434. [CrossRef]

23. Tumba, K.; Reddy, P.; Naidoo, P.; Ramjugernath, D.; Eslamimanesh, A.; Mohammadi, A.H.; Richon, D. Phase equilibria of methane and carbon dioxide clathrate hydrates in the presence of aqueous solutions of tributylmethylphosphonium methylsulfate ionic liquid. J. Chem. Eng. Data 2011, 56, 3620-3629. [CrossRef]

24. Sabil, K.M.; Nashed, O.; Lal, B.; Ismail, B.; Japper-Jaafar, A. Experimental investigation on the dissociation conditions of methane hydrate in the presence of imidazolium-based ionic liquids. Thermodyn. J. Chem. 2015, 84, 7-13.

25. Herri, J.-M.; Bouchemoua, A.; Kwaterski, M.; Fezoua, A.; Ouabbas, Y.; Cameirao, A. Gas hydrate equilibria for $\mathrm{CO}_{2}-\mathrm{N}_{2}$ and $\mathrm{CO}_{2}-\mathrm{CH}_{4}$ gas mixtures-Experimental studies and thermodynamic modelling. Fluid Phase Equilibria 2011, 301, 171-190. [CrossRef]

26. Kvamme, B.; Lund, A. The influence of gas-gas interactions on the Langmuir-constants for some natural gas hydrates. Fluid Phase Equilibria 1993, 90, 15-44. [CrossRef]

27. Kvamme, B.; Førrisdahl, O.K. Polar guest-molecules in natural gas hydrates. Fluid Phase Equilibria 1993, 83, 427-435. [CrossRef]

28. Harris, J.G.; Yung, K.H. Carbon dioxide's liquid-vapor coexistence curve and critical properties as predicted by a simple molecular model. J. Phys. Chem. 1995, 99, 12021-12024. [CrossRef]

29. Kvamme, B.; Graue, A.; Kuznetsova, T.; Buanes, T.; Ersland, G. Storage of $\mathrm{CO}_{2}$ in natural gas hydrate reservoirs and the effect of hydrate as an extra sealing in cold aquifers. Int. J. Greenh. Gas Control 2007, 1, 236-246. [CrossRef]

30. Buanes, T. Mean-Field Approaches Applied to Hydrate Phase Transition. Ph.D. Thesis, University of Bergen, Bergen, Norway, 2006.

31. Uchida, T.; Ikeda, I.Y.; Takeya, S.; Ebinuma, T.; Nagao, J.; Narita, H. $\mathrm{CO}_{2}$ hydrate film formation at the boundary between $\mathrm{CO}_{2}$ and water: Effects of temperature, pressure and additives on the formation rate. J. Cryst. Growth 2002, 237-239 Pt 1, 383-387. [CrossRef]

32. Kvamme, B.; Kuznetsova, T.; Kivelæ, P.-H. Adsorption of water and carbon dioxide on hematite and consequences for possible hydrate formation. Phys. Chem. Chem. Phys. 2012, 14, 4410-4424. [CrossRef] [PubMed]

33. Van Cuong, P. Transport and Adsorption of $\mathrm{CO}_{2}$ and $\mathrm{H}_{2} \mathrm{O}$ on Calcite and Clathrate Hydrate. Ph.D. Thesis, University of Bergen, Bergen, Norway, 2012.

34. Mohammad, N. Heterogeneous Hydrate Nucleation on Calcite $\{1014\}$ and Kaolinite \{001\} Surfaces: A Molecular Dynamics Simulation Study. Master's Thesis, University of Bergen, Bergen, Norway, 2016.

35. Qasim, M.; Kvamme, B.; Baig, K. Modeling Dissociation and Reformation of Methane and Carbon Dioxide Hydrate using Phase Field Theory with implicit hydrodynamics. In Proceedings of the 7th International Conference on Gas Hydrate (ICGH7), Edinburgh, Scotland, 17-21 July 2011.

36. Qasim, M.; Baig, K.; Kvamme, B.; Bauman, J. Mix Hydrate formation by $\mathrm{CH}_{4}-\mathrm{CO}_{2}$ exchange using Phase Field Theory with implicit Thermodynamics. Int. J. Energy Environ. 2012, 6, 479-487. 
37. Darnell, K.N.; Flemings, P.B.; DiCarlo, D. Nitrogen-Driven Chromatographic Separation During Gas Injection into Hydrate-Bearing Sediments. Water Resour. Res. 2019. [CrossRef]

38. Austvik, T.; Hustvedt, E.; Gjertsen, L.H. Formation and Removal of Hydrate Plugs-Field Trial at Tommeliten. In Proceedings of the 76 Annual Meeting of the Gas Processors Association (GPA), San Antonio, TX, USA, 10-12 March 1997; p. 249. 